\title{
RKTG overexpression inhibits proliferation and induces apoptosis of human leukemia cells via suppression of the ERK and PI3K/AKT signaling pathways
}

\author{
YINGDONG XU ${ }^{1}, \mathrm{NADENG}^{2},{\mathrm{XIAOOU} W \mathrm{WNG}^{3} \text {, YINGHUI CHEN }}^{3}, \mathrm{GUIJI}^{3}$ and HUA FAN ${ }^{3}$ \\ ${ }^{1}$ Department of Hematology, The First Affiliated Hospital of China Medical University, Shenyang, Liaoning 110001; \\ Departments of ${ }^{2}$ Oncology and ${ }^{3}$ Hematology, The Fourth Affiliated Hospital of China Medical University, \\ Shenyang, Liaoning 110032, P.R. China
}

Received February 5, 2016; Accepted January 19, 2017

DOI: $10.3892 / \mathrm{ol} .2017 .6182$

\begin{abstract}
Raf kinase trapping to Golgi (RKTG) is reported to be a tumor suppressor in a number of solid tumors due to its negative modulation of the Ras/Raf/mitogen-activated protein kinase kinase/extracellular signal-regulated kinase (ERK) pathways. However, the role of RKTG in the progression of leukemia remains unknown. In the present study, a human leukemia U937 cell line overexpressing RKTG was established, and the effect of RKTG on proliferation, cell cycle and apoptosis of human leukemia cells was analyzed. The results of the present study demonstrated that exogenous overexpression of RKTG significantly inhibited cell proliferation, which was accompanied by cell cycle arrest. Apoptosis assay and Hoechst staining demonstrated that the percentage of apoptotic cells in RKTG overexpressing cells was markedly increased. Furthermore, western blotting showed that RKTG overexpression significantly increased the level of cleaved caspase 3, B-cell lymphoma 2 (Bc12)-associated $\mathrm{X}$ apoptosis regulator and reduced the level of Bcl-2. In addition, the activation of ERK and phosphoinositide 3-kinase (PI3K)/AKT serine/threonine kinase 1 signaling pathways in human leukemia cells was also suppressed by RKTG overexpression. In conclusion, the present study demonstrated the tumor-suppressive effect of RKTG on human leukemia cells, which seem to be partially dependent on the suppression of ERK and PI3K/AKT signaling. Overexpression of RKTG may be a potential therapeutic target for the treatment of leukemia.
\end{abstract}

Correspondence to: Dr Hua Fan, Department of Hematology, The Fourth Affiliated Hospital of China Medical University, 4 East Chongshan Road, Shenyang, Liaoning 110032, P.R. China E-mail: adofcmu@163.com

Key words: acute myeloid leukemia, Raf kinase trapping to Golgi, proliferation, apoptosis, extracellular signal-regulated kinase, phosphatidylinositol 3-kinase/AKT serine/threonine kinase 1

\section{Introduction}

Acute myeloid leukemia (AML) is a heterogeneous group of neoplastic hematologic disorders characterized by differentiation arrest of hematopoiesis, which leads to uncontrolled proliferation and accumulation of clonal cells that are blocked at various steps of maturation $(1,2)$. The main clinical symptoms of AML are anemia, hemorrhage, fever, lymphadenectasis and musculoskeletal pain (3). AML accounts for 3\% of total incidences of malignant tumors. There are $\sim 257,000$ mortalities from leukemia annually worldwide (4). Despite considerable advances, chemotherapy remains the primary therapeutic approach for the treatment of leukemia, the prognosis remains poor and the 5-year survival rate has remained at $15-30 \%$ since the $1970 \mathrm{~s}(2,5,6)$. It has been reported that genetic alterations are involved in leukemogenesis $(7,8)$, thus manipulating myeloid maturation-associated genes may lead to potential therapies $(9,10)$. Therefore, investigating the underlying molecular mechanisms is important for a comprehensive study of the progression of leukemia and for the identification of novel candidate targets for therapy.

Raf kinase trapping to Golgi (RKTG) is a member of progestin and adipoQ receptor family and also a membrane protein of the Golgi apparatus. Previous studies have reported that RKTG functions as a spatial regulator of Raf kinase by binding it to the Golgi apparatus. Therefore, RKTG has an inhibitory effect on Ras/Raf/mitogen-activated protein kinase kinase (MEK)/extracellular signal-regulated kinase (ERK) signaling $(11,12)$. The Ras/Raf/MEK/ERK signaling pathway is responsible for the extracellular signal transduction into the nucleus, therefore it has a pivotal role in regulation of fundamental cellular functions, including cell proliferation, apoptosis, metabolism and differentiation (13). Studies have demonstrated that RKTG can act as a tumor suppressor in human malignant melanoma cells (12), renal cell carcinoma (14), colorectal cancer (15), laryngeal squamous cell carcinoma (16) and osteosarcoma (17). Deletion of RKTG markedly increased the incidence of chemical carcinogen-induced tumorigenesis in the mouse skin (14). However, to the best of our knowledge, whether RKTG is implicated in the progress of leukemia remains to be investigated. 
In the present study, RKTG was exogenously expressed in the human leukemia cell line U937. The present study demonstrated for the first time to the best of our knowledge that RKTG is able to markedly impair cell viability and induce apoptosis of U937 cells. Furthermore, RKTG overexpression suppressed the activation of the ERK and phosphoinositide 3-kinase (PI3K)/AKT signaling pathways in the U937 cell line. In summary, the present study uncovered a tumor-suppressive effect of RKTG in leukemia cell lines.

\section{Materials and methods}

Cell culture. Human leukemia cell line U937 was obtained from the Cell Bank of Type Culture Collection Center of the Chinese Academy of Science (Shanghai, China). Cells were cultured with RPMI-1640 medium (Gibco; Thermo Fisher Scientific, Inc., Waltham, MA, USA) containing $10 \%$ fetal bovine serum (HyClone; GE Healthcare Life Sciences, Logan, UT, USA), $100 \mathrm{U} / \mathrm{ml}$ penicillin and $100 \mu \mathrm{g} / \mathrm{ml}$ streptomycin at $37^{\circ} \mathrm{C}$ in a humidified incubator with $5 \% \mathrm{CO}_{2}$.

Plasmid construction and cell transfection. The coding sequence of RKTG was amplified by quantitative polymerase chain reaction (qPCR) using a forward primer, 5'-CGCAAGCTTATGCATCAGAAGCTGCTGA-3' and a reverse primer, 5'-CACGCTCGAGTCAAACAAGCA AATACAGGT-3'. The products were double digested by HindIII/XhoI restriction enzymes (Fermentas; Thermo Fisher Scientific, Inc., Pittsburgh, PA, USA) and inserted into the pcDNA3.1 plasmid by using UltraPower pUM-T fast clone kit (BioTek China, Beijing, China). Positive clones were screened by $100 \mu \mathrm{g} / \mathrm{ml}$ ampicillin and identified by automated sequencing. For transfection, U937 cells were seeded into 6-well plates at a density of $5 \times 10^{5}$ cells/well and grown to $70-80 \%$ confluence. The U937 cells were subsequently transfected with pcDNA3.1 vector or pcDNA3.1-RKTG using Lipofectamine 2000 (Invitrogen; Thermo Fisher Scientific, Inc.) according to the manufacturer's protocol. G418 $(600 \mu \mathrm{g} / \mathrm{ml})$ was added to the medium $48 \mathrm{~h}$ following transfection, and the stable transfected clones were selected for 2 weeks. Finally, RKTG expression in the stable transfected cell line was examined by qPCR and western blotting.

Reverse transcription (RT)-qPCR. Total RNA of the cells was extracted using RNApure Rapid Total RNA Extraction kit (BioTek China) and reverse transcribed by Super M-MLV Reverse Transcriptase (BioTek China). SYBR-Green-based qPCR was performed by using $2 X$ Power Taq PCR MasterMix (Beijing Solarbio Science and Technology Co., Ltd., Beijing, China) with $\beta$-actin employed as an internal control. The sequences of the primers used were as follows: RKTG forward, 5'-GCTTTGCTCT-GTGGGCTAT-3' and reverse, 5'-TGCGTGAGGTAATTGGGAT-3'; and $\beta$-actin forward, 5'-CTT-AGTTGCGTTACACCCTTTCTTG-3' and reverse, 5'-CTGTCACCTTCACCGTTCCAGTTT-3'. The full PCR cycling conditions were as follows: $95^{\circ} \mathrm{C} 10 \mathrm{~min} ; 95^{\circ} \mathrm{C} 10 \mathrm{sec}$, $60^{\circ} \mathrm{C} 20 \mathrm{sec}, 72^{\circ} \mathrm{C} 30 \mathrm{sec}$, for 40 cycles. The levels of RKTG were normalized to the levels of $\beta$-actin using the $2^{-\Delta \Delta \mathrm{Ct}}$ method, as previously described (18).

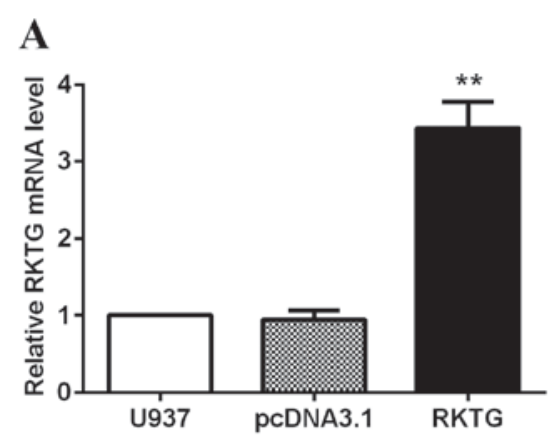

\section{B}
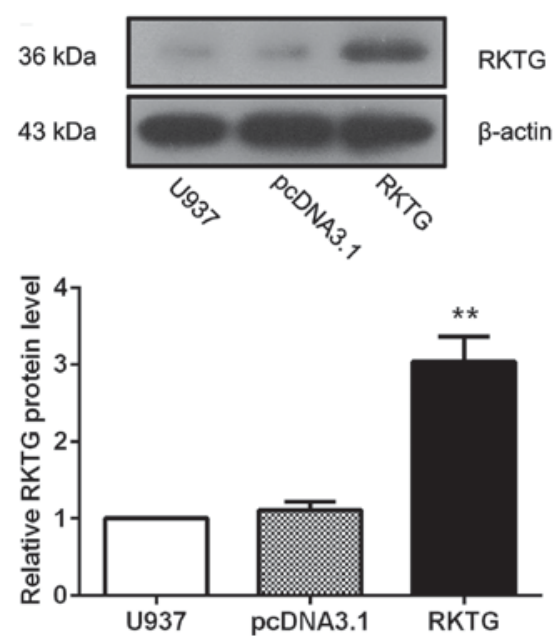

Figure 1. Overexpression of RKTG in U937 human leukemia cells. The relative levels of RKTG (A) mRNA and (B) protein were determined by quantitative polymerase chain reaction and western blotting. $\beta$-actin was employed as an internal control. Data are shown as the mean \pm standard deviation of 3 repeats. ${ }^{* *} \mathrm{P}<0.01$ vs. cells transfected with pcDNA3.1. RKTG, Raf kinase trapping to Golgi.

Western blotting. Cells from the U937 group, pcDNA3.1 transfected group and RKTG transfected group were lysed by radioimmunoprecipitation assay buffer solution (Beyotime Institute of Biotechnology, Haimen, China). The concentration of total protein was measured using BCA protein assay kit (Beyotime Institute of Biotechnology). A total of $40 \mu \mathrm{g}$ protein was subjected to 5, 10 or $13 \%$ SDS-PAGE and transferred onto polyvinylidene fluoride membranes (EMD Millipore, Billerica, MA, USA). Following blocking with $5 \%(\mathrm{~m} / \mathrm{v})$ fat-free milk, the membranes were incubated at $4^{\circ} \mathrm{C}$ overnight with primary antibodies: Anti-RKTG (1:200; sc-161992; Santa Cruz Biotechnology, Inc., Dallas, TX, USA), anti-cleaved caspase 3 (1:1,000; ab2302; Abcam, Cambridge, MA, USA), anti-B-cell lymphoma 2 (anti-Bcl-2; 1:400; BA0412; Wuhan Boster Biological Technology, Ltd., Wuhan, China), anti-Bcl-2-associated X, apoptosis regulator (anti-Bax; BA0315; 1:400; Wuhan Boster Biological Technology, Ltd.), anti-phosphorylated (p)-mitogen-activated protein kinase 1 (anti-p-ERK; 1:500; bs-1522R; BIOSS, Beijing, China), anti-ERK (1:500; bs-2637R; BIOSS), anti-p-AKT serine/threonine kinase 1 (anti-p-AKT; 1:200; sc-135651; Santa Cruz Biotechnology, Inc.), anti-AKT (1:200; sc-8312; Santa Cruz Biotechnology, Inc.), anti-p-glycogen synthase kinase-3 $\beta$ (anti-p-GSK-3ß; sc-11757; 1:200; Santa Cruz Biotechnology, Inc.) or anti-GSK-3 $\beta$ (1:200; sc-9166; Santa Cruz Biotechnology, 
A
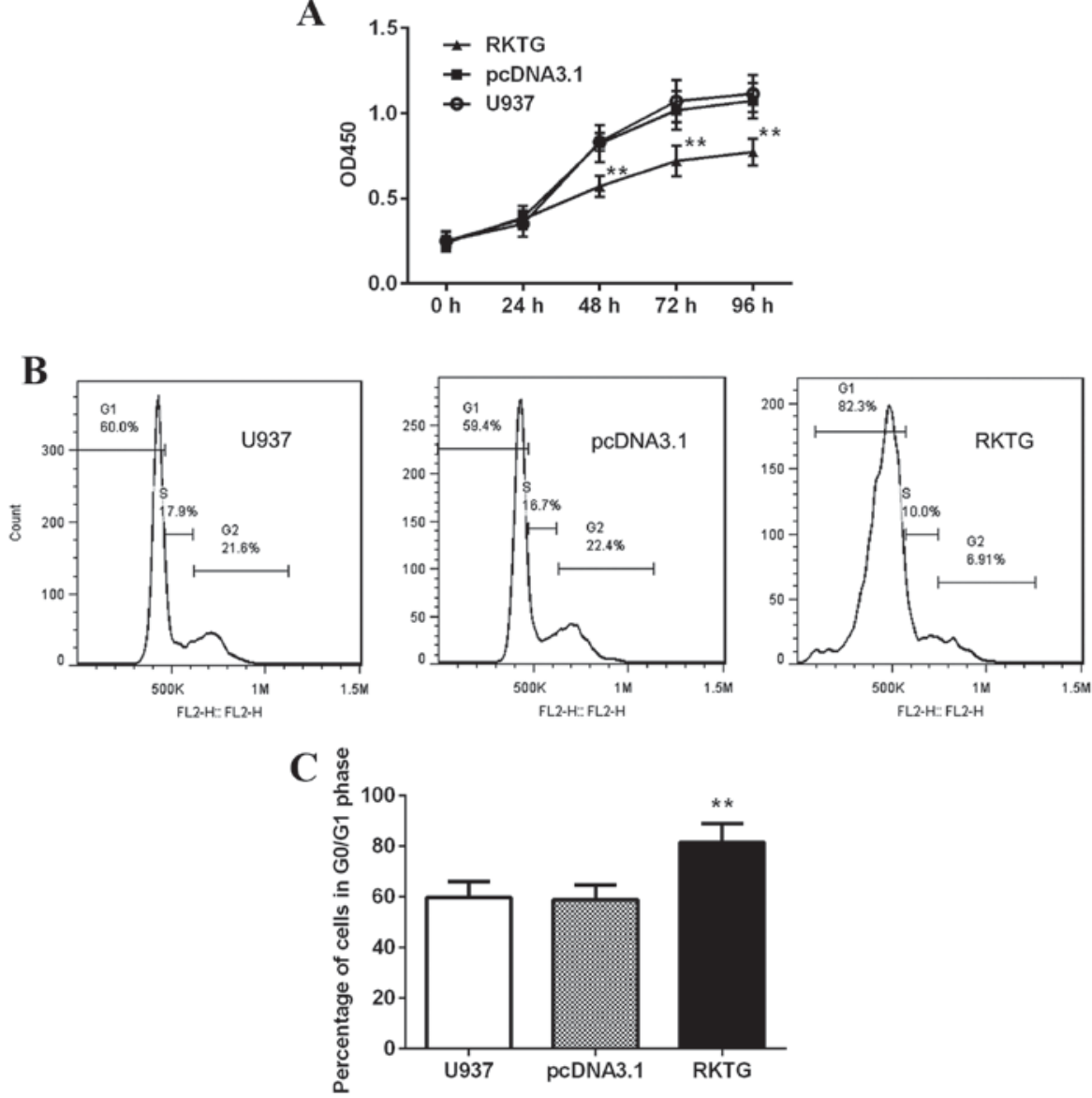

Figure 2. Overexpression of RKTG inhibits cell proliferation and induces cell cycle arrest in leukemia cells. (A) The proliferation of U937 cells at various time intervals was measured by cell-counting kit- 8 assay. Data are shown as the mean \pm standard deviation of 5 repeats. (B) Cell cycle was analyzed by flow cytometry, and the $(\mathrm{C})$ percentage of cells in G0/G1 phase was presented as the mean \pm standard deviation of 3 repeats. ${ }^{* *} \mathrm{P}<0.01$ vs. cells transfected with pcDNA3.1. RKTG, Raf kinase trapping to Golgi; OD, optical density.

Inc.). Specific bands were detected by horseradish peroxidase conjugated goat anti-rabbit (1:5,000; A0208; Beyotime Institute of Biotechnology) or goat anti-mouse $\operatorname{IgG}$ (1:5,000; A0216; Beyotime Institute of Biotechnology) at $37^{\circ} \mathrm{C}$ for $45 \mathrm{~min}$ and visualized using enhanced chemiluminescence (ECL) kit (Qihai Biotechnology, Shanghai, China).

Cell-counting kit-8(CCK-8) assay. Cells from the U937 group, pcDNA3.1 transfected group and RKTG transfected group were seeded in 96 -well plates $\left(2 \times 10^{3}\right.$ cells/well) and cultured in a humidified atmosphere $\left(5 \% \mathrm{CO}_{2}\right)$ at $37^{\circ} \mathrm{C}$. The $\mathrm{CCK}-8$ solution (Beyotime Institute of Biotechnology) was added at 0 , $24,48,72$ and $96 \mathrm{~h}$ prior to an additional $1 \mathrm{~h}$ incubation. The optical density values at $450 \mathrm{~nm}$ were subsequently measured with a microplate reader (ELx-800; BioTek Instruments, Inc., Winooski, VT, USA).

Flow cytometry. For cell cycle analysis, $1 \times 10^{6}$ cells from each group were fixed by $70 \%$ ethanol at $4^{\circ} \mathrm{C}$ for $2 \mathrm{~h}$. Following washing with PBS twice, cells were re-suspended in $500 \mu 1$ staining buffer and incubated with $25 \mu \mathrm{l}$ propidium iodide (PI) (Wanleibio, Shenyang, China) at $37^{\circ} \mathrm{C}$ for $30 \mathrm{~min}$ in the dark. Apoptotic cells were assessed by Annexin V-fluorescein isothiocyanate (FITC)/PI double-staining cell apoptosis kit (Nanjing KeyGen Biotech Co., Ltd., Nanjing, China) according to the manufacturer's instructions. Briefly, the cells were stained with $5 \mu \mathrm{l}$ Annexin V-FITC and $5 \mu \mathrm{l}$ PI for $15 \mathrm{~min}$ at room temperature in the dark. The proportion of cells in each cell cycle phase and apoptotic state was measured by flow cytometry (BD Accuri C6; BD Biosciences, Franklin Lakes, NJ, USA). Data were processed using matched Accuri CFlow Plus software (version 1.0.1727; BD Accuri Cytometers Inc., MI, USA).

Hoechst staining. Hoechst staining was performed using a Hoechst 33258 staining kit (Wanleibio). Briefly, cells from each group were plated in a 12 -well plate with a coverslip at a density of $2 \times 10^{4}$ cells/well and grown at $37^{\circ} \mathrm{C}$ for $24 \mathrm{~h}$. Following fixation with $4 \%$ paraformaldehyde for $20 \mathrm{~min}$ at room temperature, cells were stained with $2 \mu \mathrm{l} / \mathrm{ml}$ Hoechst staining solution and washed with phosphate buffer solution two times. The slides were mounted and apoptotic nuclei were observed under a fluorescence microscope (IX53; Olympus Corporation, Tokyo, Japan).

Statistical analysis. Statistical analysis was performed by SPSS version 16.0 software (SPSS, Inc., Chicago, IL, USA). Results are expressed as the mean \pm standard deviation. 

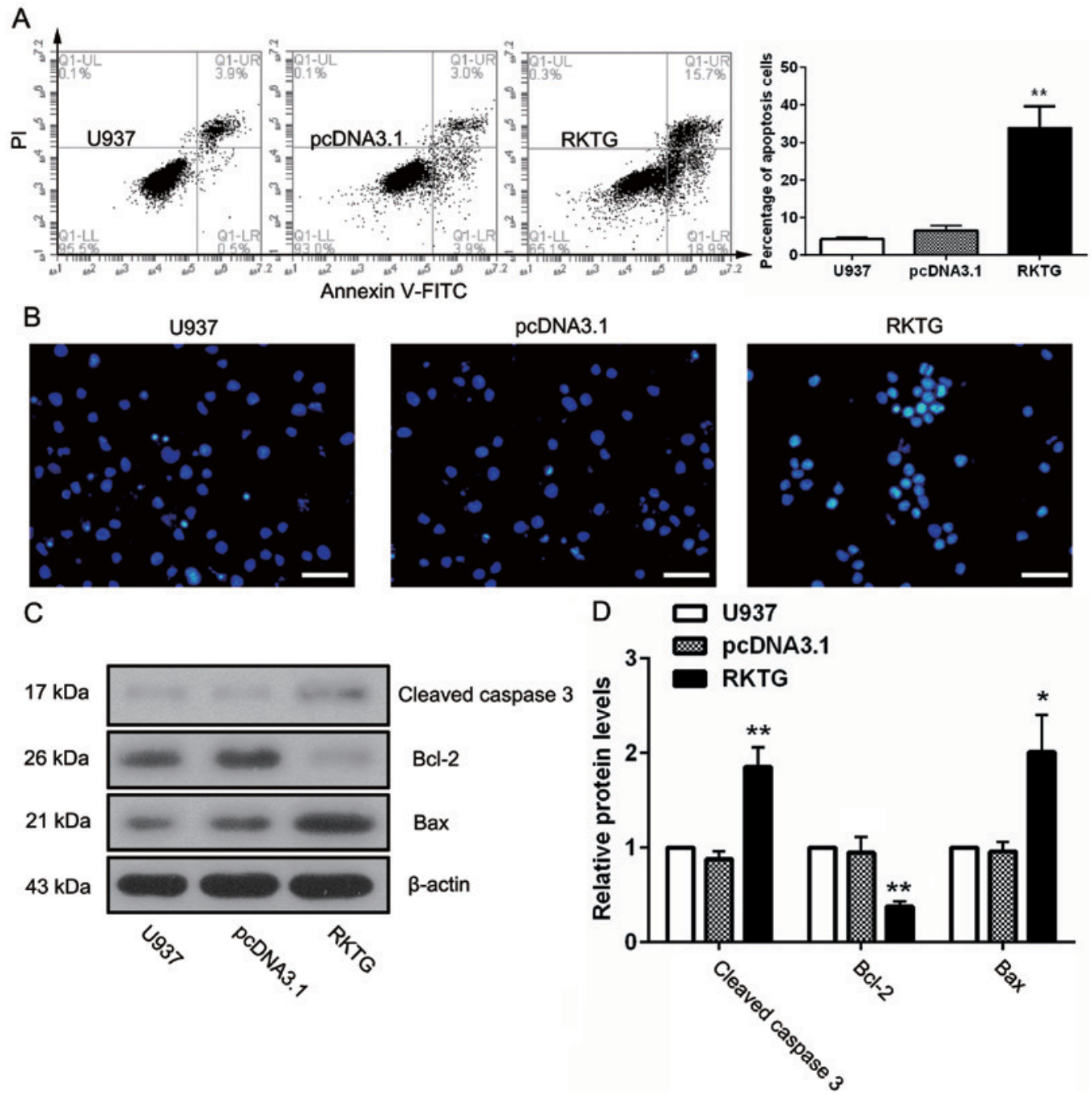

Figure 3. Overexpression of RKTG induces apoptosis of leukemia cells. Apoptosis status of U937 cells was analyzed by (A) flow cytometry and (B) Hoechst staining. Scale bar, $50 \mu \mathrm{m}$. Images are representative of 3 experimental replicates. (C) Expression of apoptosis-associated proteins were determined by western blotting and (D) the relative protein levels were presented as the mean \pm standard deviation of 3 repeats. ${ }^{*} \mathrm{P}<0.05,{ }^{* * *} \mathrm{P}<0.01 \mathrm{vs}$. cells transfected with pcDNA3.1. Bcl-2, B-cell lymphoma 2; BAX, Bcl-2-associated X, apoptosis regulator; FITC, fluorescein isothiocyanate; PI, propidium iodide; RKTG, Raf kinase trapping to Golgi.

Differences between groups were compared by one-way analysis of variance followed by the least significant difference post hoc test. $\mathrm{P}<0.05$ was considered to indicate a statistically significant difference.

\section{Results}

Establishment of RKTG overexpressing human leukemia cell line. To investigate the biological function of RKTG in the progression of leukemia, human leukemia cell line U937 was transfected either with pcDNA3.1-RKTG that contained the full-length coding sequence of RKTG or the vector pcDNA3.1, which served as a negative control. The G418-resistant clones were subsequently selected, and the expression of RKTG was determined by RT-qPCR and western blotting. As expected, in cells transfected with pcDNA3.1-RKTG, the level of RKTG mRNA was significantly upregulated compared with the pcDNA3.1-transfected group $(3.43 \pm 0.35$ vs. $0.95 \pm 0.12 ; \mathrm{P}<0.01$; Fig. 1A). In addition, the protein level of RKTG was also significantly increased following transfection with pcDNA3.1-RKTG compared with the pcDNA3.1-transfected group (3.04 \pm 0.33 vs. $1.10 \pm 0.11 ; \mathrm{P}<0.01$; Fig. 1B). The RKTG overexpressing leukemia cell line was subsequently maintained in culture medium containing $300 \mu \mathrm{g} / \mathrm{ml} \mathrm{G} 418$ for further investigation.

Overexpression of RKTG suppresses proliferation of human leukemia cells. To evaluate the effect of RKTG on leukemia cell growth, proliferation rate and cell cycle was analyzed by CCK-8 assay and flow cytometry. As shown in Fig. 2A, compared with the control group, exogenous expression of RKTG significantly inhibited the proliferation of leukemia cells at 48, 72 and $96 \mathrm{~h}(\mathrm{P}<0.01)$. Additionally, overexpression of RKTG significantly increased the percentage of G0/G1 phase cells $(81.43 \pm 7.44 \%$ vs. $58.87 \pm 5.82 \%$; $\mathrm{P}<0.05$; Fig. 2B and C). However, the proportion of cells in G2/M phase was significantly reduced when compared with the pcDNA3.1 transfected group (7.24 $\pm 5.21 \%$ vs. $23.73 \pm 2.57 \%$; $\mathrm{P}<0.01$; Fig. 2B and C). Collectively, these results indicate that RKTG overexpression induced cell cycle arrest and inhibited proliferation of human leukemia cells. 
A

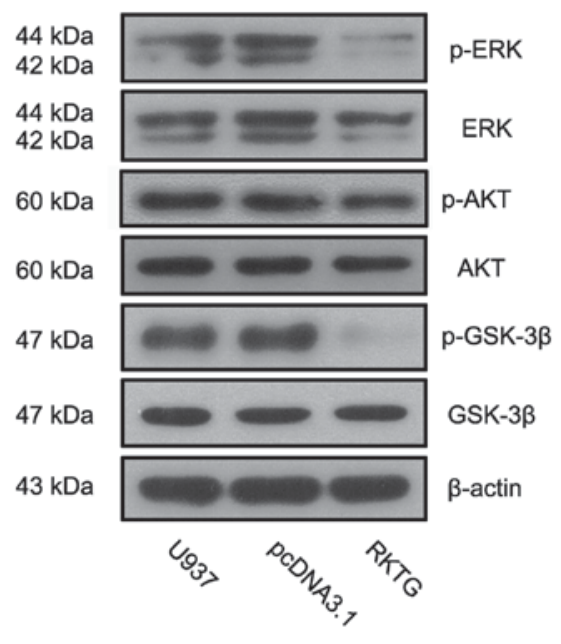

B

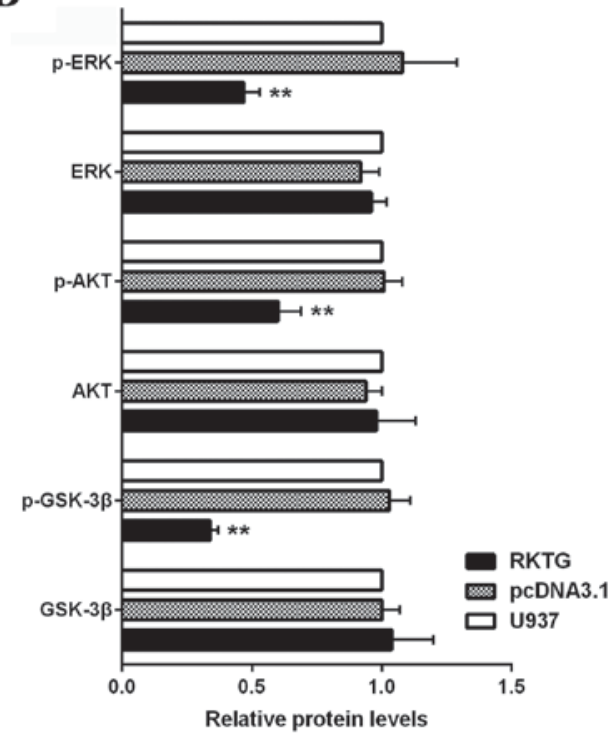

Figure 4. Overexpression of RKTG suppresses the activity of ERK and PI3K/AKT signaling pathways. The expression of the key components of ERK and $\mathrm{PI} 3 \mathrm{~K} / \mathrm{AKT}$ signaling was measured by (A) western blotting (B) and the relative levels are presented as the mean \pm standard deviation of 3 repeats. ${ }^{* *} \mathrm{P}<0.01$ vs. cells transfected with pcDNA3.1. ERK, extracellular signal-regulated kinase; GSK-3 $\beta$, glycogen synthase kinase $3 \beta$; p, phosphorylated; PI3K, phosphoinositide 3-kinase; RKTG, Raf kinase trapping to Golgi.

Overexpression of RKTG induces apoptosis of human leukemia cells. To investigate the role of RKTG in cell apoptosis, U937 cells from each experimental group were stained with Annexin V-FITC and PI. The cells were subsequently subjected to flow cytometry. The results demonstrated that overexpression of RKTG in leukemia cells resulted in a marked increase in the rate of apoptosis as compared with the negative control $(33.80 \pm 5.81 \%$ vs. $6.54 \pm 1.22 \%$; $\mathrm{P}<0.01$; Fig. $3 \mathrm{~A})$. This finding was further verified by Hoechst staining, (Fig. 3B). Apoptotic nuclei were observed in the cells overexpressing RKTG, which were characterized by brilliant blue staining of the apoptotic bodies, but not in the other groups. Furthermore, several apoptosis-associated proteins were also examined, as shown in Fig. 3C and D. When compared with pcDNA3.1 group, the level of anti-apoptotic protein Bcl-2 was markedly decreased $(\mathrm{P}<0.01)$, whilst the levels of proapoptotic protein cleaved caspase 3 and Bax were significantly upregulated by RKTG overexpression $(\mathrm{P}<0.01, \mathrm{P}<0.05)$.

Overexpression of RKTG suppresses ERK and PI3K/AKT signaling in human leukemia cells. To assess whether ERK or PI3K/AKT signaling pathways are implicated in the RKTG-associated anticancer effect in leukemia cells, the expression of the key components of these pathways was measured by western blotting. The results demonstrated that the levels of p-ERK, p-AKT and p-GSK-3 $\beta$ were all significantly reduced in RKTG overexpression cells when compared with the cells transfected with the vector alone $(0.47 \pm 0.06$ vs. $1.08 \pm 0.21 ; \mathrm{P}<0.01 ; 0.52 \pm 0.07$ vs. $1.01 \pm 0.06 ; \mathrm{P}<0.01$; $0.34 \pm 0.03$ vs. $1.03 \pm 0.8 ; \mathrm{P}<0.05$; Fig. 4). Therefore, exogenous expression of RKTG suppressed the activation of ERK and PI3K/AKT signaling pathways in leukemia cells, which may be a molecular mechanism for how RKTG inhibits proliferation and induces apoptosis of leukemia cells.

\section{Discussion}

RKTG has been reported to be closely associated with the progression of different types of malignant cancer cells $(14,19)$. However, the role of RKTG in the proliferation and apoptosis of leukemia cells remains to be fully elucidated. In the present study, the exogenous overexpression of RKTG significantly inhibited cell proliferation, blocked cell cycle progression, induced apoptosis and suppressed the activation of ERK and PI3K/AKT signaling pathways in leukemia cells. These results have provided evidence that RKTG may be a tumor suppressor in human leukemia cells.

RKTG is a spatial regulator of Raf-1 (11) and acts as an anticancer factor due to its inhibitory activity on Raf/MEK/ERK signaling $(12,14,20)$. RKTG expression in the colorectal cancer samples was significantly reduced compared with adjacent normal tissues. Furthermore, RKTG expression was inversely correlated with the tumor grade in colorectal cancer (15). The proliferation rate of colon cancer cells was inhibited by RKTG overexpression. By contrast, lentiviral-mediated knockdown of RKTG markedly increased the proliferation rate of colon cancer cells (15). In addition, overexpression of RKTG in A375 melanoma cells resulted in a reduction in growth rate and colony-forming activity (12). In accordance with these studies, the present study demonstrated that exogenous expression of RKTG suppressed the proliferation of human leukemia cells. RKTG overexpression resulted in an increase in the number of cells in the G0/G1 phase. Therefore, overexpression of RKTG may inhibit leukemia cell proliferation by arresting the cell cycle in G0/G1 phase.

Xie et al (20) reported that, when treated with chemical carcinogens, the number of apoptotic cells in RKTG-deficient mice was significantly reduced compared with the number of cells in wild-type mice. The apoptotic status of RKTG overexpressing leukemia cells was also examined in the present study. 
The results demonstrated that upregulation of RKTG markedly promoted the apoptosis of leukemia cells. To further elucidate the potential mechanisms of RKTG-mediated apoptosis, the level of apoptosis-associated proteins was also determined. Caspase- 3 is a pivotal executor of apoptosis. The activation and cleavage of caspase- 3 is a marker of irreversible apoptosis (21). The antiapoptotic protein $\mathrm{Bcl}-2$ and proapoptotic protein Bax are key regulators of mitochondrial-mediated apoptosis (22). In the present study, exogenous overexpression of RKTG strongly increased the levels of cleaved caspase 3 and Bax, and decreased the expression of $\mathrm{Bcl}-2$, suggesting that RKTG is able to induce apoptosis in leukemia cells.

The activation of intracellular signaling pathways is a critical determinant of the biological outcome of cancer cells (23). Aberrant upregulation of the Raf/MEK/ERK and PI3K/AKT pathways is frequently observed in leukemia patients, and these changes are closely associated with poor prognosis (24-27). The inhibitory activity of RKTG on Raf/MEK/ERK signaling has been reported in several tumor cell lines $(11,12,14,15,20)$. Additionally, the activation of the PI3K/AKT signaling pathway induced by G $\beta 1 \gamma 2$ overexpression in monkey kidney fibroblast cells COS7 has been previously reported to be markedly abrogated by RKTG co-overexpression (28). The present study demonstrated that upregulation of RKTG significantly suppressed the activation of ERK and PI3K/AKT signaling pathways. Since the blockade of ERK or PI3K/AKT pathways is able to induce apoptosis and increase drug sensitivity of leukemia cells $(29,30)$, the present authors speculate that RKTG may inhibit proliferation and induce apoptosis of leukemia cells, partly by the suppression of ERK and PI3K/AKT signaling pathways.

In summary, the results of the present study demonstrate that overexpression of RKTG is able to inhibit cell proliferation, induce cell cycle arrest and cause apoptosis of leukemia cells. These effects of RKTG in leukemia cells may be associated with the inhibition of ERK and activation of PI3K/AKT signaling. These findings indicate that overexpression of RKTG may serve as a promising strategy for the treatment of leukemia.

\section{References}

1. Estey E and Döhner H: Acute myeloid leukaemia. Lancet 368: 1894-1907, 2006.

2. Smith M, Barnett M, Bassan R, Gatta G, Tondini C and Kern W: Adult acute myeloid leukaemia. Crit Rev Oncol Hematol 50: 197-222, 2004

3. Lowenberg B, Downing JR and Burnett A: Acute myeloid leukemia. N Engl J Med 341: 1051-1062, 1999.

4. Jemal A, Siegel R, Xu J and Ward E: Cancer statistics, 2010. CA Cancer J Clin 60: 277-300, 2010.

5. Tallman MS, Gilliland DG and Rowe JM: Drug therapy for acute myeloid leukemia. Blood 106: 1154-1163, 2005.

6. Ferrara F: Unanswered questions in acute myeloid leukaemia. Lancet Oncol 5: 443-450, 2004.

7. Look AT: Oncogenic transcription factors in the human acute leukemias. Science 278: 1059-1064, 1997.

8. Castilla LH, Garrett L, Adya N, Orlic D, Dutra A, Anderson S, Owens J, Eckhaus M, Bodine D and Liu PP: The fusion gene Cbfb-MYH11 blocks myeloid differentiation and predisposes mice to acute myelomonocytic leukaemia. Nat Genet 23 . 144-146, 1999.

9. Falini B, Nicoletti I, Martelli MF and Mecucci C: Acute myeloid leukemia carrying cytoplasmic/mutated nucleophosmin (NPMc+ AML): Biologic and clinical features. Blood 109: 874-885, 2007.
10. Christiansen DH, Andersen MK, Desta F and Pedersen-Bjergaard J: Mutations of genes in the receptor tyrosine kinase (RTK)/RAS-BRAF signal transduction pathway in therapy-related myelodysplasia and acute myeloid leukemia. Leukemia 19: 2232-2240, 2005.

11. Feng L, Xie X, Ding Q, Luo X, He J, Fan F, Liu W, Wang Z and Chen Y: Spatial regulation of Raf kinase signaling by RKTG. Proc Natl Acad Sci USA 104: 14348-14353, 2007.

12. Fan F, Feng L, He J, Wang X, Jiang X, Zhang Y, Wang Z and Chen Y: RKTG sequesters B-Raf to the Golgi apparatus and inhibits the proliferation and tumorigenicity of human malignant melanoma cells. Carcinogenesis 29: 1157-1163, 2008.

13. Cano E and Mahadevan LC: Parallel signal processing among mammalian MAPKs. Trends Biochem Sci 20: 117-122, 1995.

14. Zhang Y, Jiang X, Qin X, Ye D, Yi Z, Liu M, Bai O, Liu W, Xie X, Wang Z, et al: RKTG inhibits angiogenesis by suppressing MAPK-mediated autocrine VEGF signaling and is downregulated in clear-cell renal cell carcinoma. Oncogene 29: 5404-5415, 2010.

15. Wang X, Li X, Fan F, Jiao S, Wang L, Zhu L, Pan Y, Wu G, Ling ZQ, Fang J and Chen Y: PAQR3 plays a suppressive role in the tumorigenesis of colorectal cancers. Carcinogenesis 33: 2228-2235, 2012

16. Wu Q, Zhuang K and Li H: PAQR3 plays a suppressive role in laryngeal squamous cell carcinoma. Tumour Biol 37: 561-565, 2016.

17. Ma Z, Wang Y, Piao T, Li Z, Zhang H, Liu Z and Liu J: The tumor suppressor role of PAQR3 in osteosarcoma. Tumour Biol 36: 3319-3324, 2015.

18. Livak KJ and Schmittgen TD: Analysis of relative gene expression data using real-time quantitative PCR and the 2(-Delta Delta C(T)) Method. Methods 25: 402-408, 2001.

19. Ling ZQ, Guo W, Lu XX, Zhu X, Hong LL, Wang Z, Wang Z and Chen Y: A Golgi-specific protein PAQR3 is closely associated with the progression, metastasis and prognosis of human gastric cancers. Ann Oncol 25: 1363-1372, 2014.

20. Xie X, Zhang Y, Jiang Y, Liu W, Ma H, Wang Z and Chen Y: Suppressive function of RKTG on chemical carcinogen-induced skin carcinogenesis in mouse. Carcinogenesis 29: 1632-1638, 2008.

21. Porter AG and Jänicke RU: Emerging roles of caspase-3 in apoptosis. Cell Death Differ 6: 99-104, 1999.

22. Oltvai ZN, Milliman CL and Korsmeyer SJ: Bcl-2 heterodimerizes in vivo with a conserved homolog, Bax, that accelerates programmed cell death. Cell 74: 609-619, 1993.

23. Marshall CJ: Specificity of receptor tyrosine kinase signaling: Transient versus sustained extracellular signal-regulated kinase activation. Cell 80: 179-185, 1995.

24. Zhao S, Konopleva M, Cabreira-Hansen M, Xie Z, Hu W, Milella M, Estrov Z, Mills GB and Andreeff M: Inhibition of phosphatidylinositol 3-kinase dephosphorylates BAD and promotes apoptosis in myeloid leukemias. Leukemia 18: 267-275, 2004.

25. Gregorj C, Ricciardi MR, Petrucci MT, Scerpa MC, De Cave F, Fazi P, Vignetti M, Vitale A, Mancini M,Cimino G, et al: ERK1/2 phosphorylation is an independent predictor of complete remission in newly diagnosed adult acute lymphoblastic leukemia. Blood 109: 5473-5476, 2007.

26. Milella M, Konopleva M, Precupanu CM, Tabe Y, Ricciardi MR, Gregorj C, Collins SJ, Carter BZ, D'Angelo C, Petrucci MT, et al: MEK blockade converts AML differentiating response to retinoids into extensive apoptosis. Blood 109: 2121-2129, 2007.

27. Milella M, Kornblau SM, Estrov Z, Carter BZ, Lapillonne H, Harris D, Konopleva M, Zhao S, Estey E and Andreeff M: Therapeutic targeting of the MEK/MAPK signal transduction module in acute myeloid leukemia. J Clin Invest 108: 851-859, 2001.

28. Jiang Y, Xie X, Zhang Y, Luo X, Wang X, Fan F, Zheng D, Wang $Z$ and Chen Y: Regulation of $G$-protein signaling by RKTG via sequestration of the $G$ betagamma subunit to the Golgi apparatus. Mol Cell Biol 30: 78-90, 2010.

29. Wu J, Wong WW, Khosravi F, Minden MD and Penn LZ: Blocking the Raf/MEK/ERK pathway sensitizes acute myelogenous leukemia cells to lovastatin-induced apoptosis. Cancer Res 64: 6461-6468, 2004.

30. Martelli AM, Nyakern M, Tabellini G, Bortul R, Tazzari PL, Evangelisti C and Cocco L: Phosphoinositide 3-kinase/Akt signaling pathway and its therapeutical implications for human acute myeloid leukemia. Leukemia 20: 911-928, 2006. 